Agricultural Journal 14 (5): 94-103, 2019

ISSN: 1816-9155

(C) Medwell Journals, 2019

\title{
The Rerelationship Between Climatic Elements and Vegetation Cover in Adamawa State, Nigeria
}

\author{
${ }^{1}$ I. Mohammed and ${ }^{2}$ I.M. Abubakar \\ ${ }^{1}$ Department of Environmental Management Technology, Faculty of Environmental Technology, \\ Abubakar Tafawa Balewa University, Bauchi, Nigeria \\ ${ }^{2}$ Department of Agricultural Education, Federal Colledge of Education Yola, Jimeta, \\ Adamawa State, Nigeria
}

\begin{abstract}
The study investigated the trend of climatic elements and its effect on vegetation cover in Adamawa state from 1988-2017. Pearson correlation coefficient was used to check the strength of relations between NDVI and the related climate elements (i.e., temperature, precipitation, relative humidity and sunshine hours) and regression analysis was further used to identify the effectiveness of each climate elements on vegetation cover. The result indicated that NDVI had a positive correlation with precipitation and temperature $(p=0.672)$ in Yola and Gyawana for three decades, followed with marginal negative correlation $(\mathrm{p}=0.000)$ in the last three decades. Ganye in the same period had slightly stable precipitation with positive correlation $(p=0.005)$ while Mubi recorded remarkable decreased of precipitation slightly negative correlation $(\mathrm{p}=0.109)$ but a slightly negative correlation with relative humidity and sunshine hours at Yala $(p=0.129)$, Gyawana $(p=0.015)$ and Ganye. Evaporation and temperature shows similar negative correlation in both study sites Yala ( $0.768 ; 0.129$ 0.263), Gyawana (0.015) and Ganye. Annual maximum temperature had noticeable increased during the study period in both study sites 2003 was recorded highest $43^{\circ} \mathrm{C}$ while 2000 was recorded lowest $31^{\circ} \mathrm{C}$ with no significant correlation in Yola $(\mathrm{p}=0.201)$. Precipitation and temperature trend exhibited a positive slope of the model line indicating overall increased in precipitation and temperature with time in Yola, Gyawana and Ganye with positive relationship with NDVI $(p=0.672 ; 0.000 ; 0.005)$ while Mubi recorded remarkable decreased with negative relationship $(\mathrm{p}=0.109)$. Evaporation, sun shine and relative humidity shows similar negative trend with low relationship in Yola and Mubi while sun shine trend increases in Ganye and relative humidity in Gyawana; it is concluded that based on the close relationship between NDVI and the major climate elements (Precipitation and Temperature) revealed in this studies, further investigations became necessary to investigate the vegetation dynamic responses to changes in the two major climate variables and establish quantitative relations between them.
\end{abstract}

Key words: Trend, effect, climatic elements, NDVI, Adamawa state

\section{INTRODUCTION}

Terrestrial ecosystems are permanently changing at a variety of spatial and temporal scales due to natural and/or anthropogenic causes leading to regional and global loss of biodiversity; these were evident in most ecological zones of Nigeria including Adamawa state and were directly linked with the current challenges of climate change (Akosim et al., 2004). Climate change is one of the causes resulting in land cover change (Adebayo, 2010; Adewumi, 2013). Evidence shows that there is a strong relationship between terrestrial vegetation coverage and climate variability (Kaufmann et al., 2003). Therefore, there is an increasing concern on the study of the relationship between vegetation cover change and the related climate elements (Fu et al., 2007; Yang et al., 2010).
Available literature has shown that remote sensing images have typically been used as a tool for the analysis of changes and for monitoring. An example is SPOT VEGETATION product which can provide the required time-series of satellite images to extract vegetation parameters and monitor dynamic trends in vegetation. Among the surface parameters extracted from remote sensing data, Normalized Difference Vegetation Index (NDVI) has proved to be a tool for monitoring the status of the aboveground biomass at the landscape level because of the high correlation with green-leaf density and net primary production (Running and Nemani, 1988; Tucker and Sellers, 1986; Wylie et al., 2003) which can be calculated by the formula NDVI = (NIR-RED)/(NIR+RED) where NIR and RED are the reflectance in the near-infrared and red electromagnetic

Corresponding Author: I. Mohammed, Department of Environmental Management Technology, Faculty of Environmental Technology, Abubakar Tafawa Balewa University, Bauchi, Nigeria 
Agric. J., 14 (5): 94-103, 2019

spectrums of objects on the Earth surface, respectively (Eidenshink and Faundeen, 1994). Climate elements such as precipitation and temperature, affect the vegetation cover and plant growth. NDVI time series have proven useful to reflect the change of vegetation cover to a certain extent (Nemani et al., 2003). Therefore, the studies on the relationship between vegetation cover (NDVI) and climate elements have become a hot topic in a much larger context of ecological research (Fu et al., 2007). Many case studies in different countries and regions have also been conducted to evaluate vegetation dynamic. As a result, several methodologies have been used to monitor vegetation dynamic from multi-temporal data including statistical methods.

Climate change is one of the environmental life-threatening phenomena to economic development and sustainability of mankind worldwide. Natural climate cycle and human activities have contributed to an increase in the accumulation of heat-trapping "greenhouse" gases in the atmosphere thereby contributing to an increase in temperature in the global climate (global warming) (UNFCCC., 2007).

Adamawa state has many growing urban areas that had its fair share of the growth of these phenomena. As a result of that there is an increase in population and the attendant infrastructural demand to meet the increasing population and their socio-economic and cultural needs. The prevalence of the insurgency in the study area (North East) where most towns and villages were deserted for safer and reliable places for habitation which may be exerted additional pressure to the existing infrastructure and other natural resources. This has influenced changes in the land use pattern both for residential, commercial and agricultural practices especially the pastoral system. Du et al. (2004) studied the relationship between human activities and climate change in the Tibetan plateau and observed that there is a positive correlation between human activities and degradation of grassland due to overgrazing with increased potential vapor transpiration level thereby promoting climate warming and the degradation process.

Adamawa state is one of the thirty six states in Nigeria, it shares boundary with Taraba state in the South and West Gombe in the Northwest and Borno to the North. Adamawa state has an international boundary with the Cameroon Republic along its Eastern border. The state covers a land area of about $38,741 \mathrm{~km}$ with a population of 3,176,950. Adamawa state is divided into 21 local government areas. The state lies within the Guinea savanna zone of Nigeria which results in rich vegetation types but with a very fragile ecosystem in part of the Gongola basin which transverse the state from North East. Specially, drought and flooding disasters frequently occur in the state and majorly along the basin leading to the consequential loss in biodiversity which is in response to regional climate change. The basin influence and dominates the ecological stability in Adamawa state. It is therefore, necessary to gain a deep and through understanding of the relationship between vegetation coverage and climate elements in the state.

The objective of the present study is to reveal the relationship between vegetation cover and major climate elements from 1988-2017 in Adamawa state using an integrated approach. Firstly, a correlation analysis was used to analyze the relationship between the major climate elements and the vegetation cover based on the data of NDVI and the climatic data from 4 meteorological stations in state using time series data. Secondly, regression analysis was further used to identify the effectiveness of each climate elements on vegetation cover change during the period of 1988-2017.

\section{MATERIALS AND METHODS}

Study area: Adamawa state is located at the North Eastern part of Nigeria. It lies between latitude $9^{\circ} 20^{\prime} 00^{\prime \prime}$ $\mathrm{N}$ of the equator and between longitude $12^{\circ} 30^{\prime} 00^{\prime \prime} \mathrm{E}$ of the Greenwich meridian. It shares boundary with Taraba state in the South and West Gombe in the Northwest and Borno to the North. Adamawa state has an international boundary with the Cameroon Republic along its Eastern border. The state covers a land area of about $38,741 \mathrm{~km}$ with a population of 3,176,950 (Census, 2006). Adamawa state is divided into 21 local government areas.

Topographically, it is a mountainous land crossed by large river valleys: the Benue, Gongola and Yedsarem. The valleys of the Cameroon, Mandara and Adamawa mountains form part of the landscape. The climate of the state is a tropical climate, conducive and accommodating agricultural practice. The mean sunshine hours in Adamawa state is adequate throughout the year to provide the drying power of the air required by the field crops and vegetation? The air temperature of Adamawa is typical of West African savannah climate. The maximum temperature can reach up to $40^{\circ} \mathrm{C}$ around April and minimum can be as low as $18^{\circ} \mathrm{C}$ in December and January, the mean temperature ranges from $26.7^{\circ} \mathrm{C}$ in Southern part to $27.8^{\circ} \mathrm{C}$ in the Northern-Eastern part in the state (Adebayo and Turker, 1999).

Annual precipitation in August ranges between 180, $250 \mathrm{~mm}$ in the Northern and Southern part of the state. In September, the rainfall is relatively high in Southern with $350 \mathrm{~mm}$ and low in the Northern part up to $150 \mathrm{~mm}$ (Adebayo and Turker, 1999).

The vegetation of the state is characterized with sub Sudan savannah vegetation and Guinea vegetation, the Northern part of Adamawa state has the sub Sudan vegetation zone marked by short grasses interspersed short trees while in its Southern part, the Northern Guinea savannah vegetation exists. Figure 1 is a map of Nigeria showing Adamawa state and the study area. 


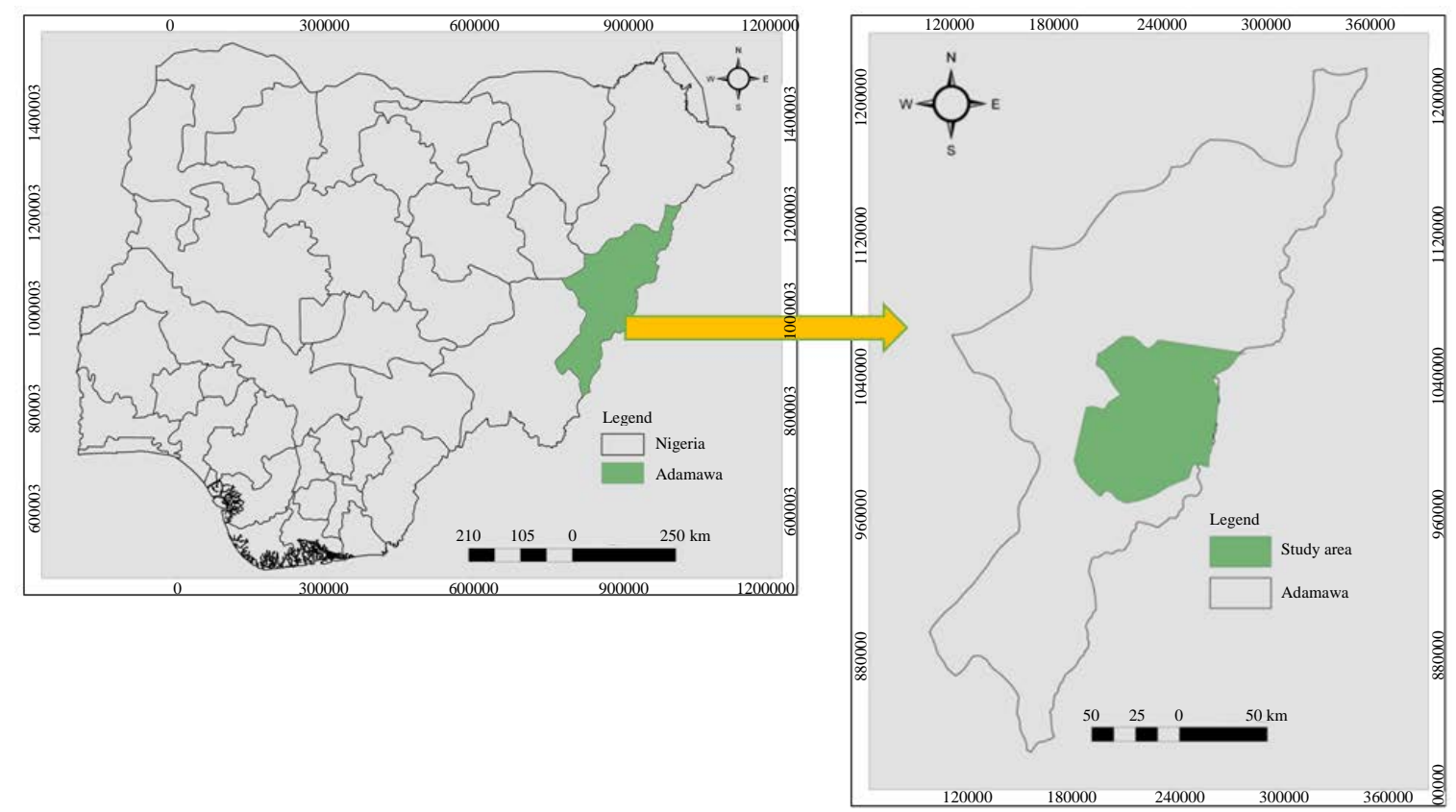

Fig. 1: Map of Nigeria showing Adamawa state and the study area

Table 1: Correlation coefficients between NDVI, climate elements and study site

\begin{tabular}{|c|c|c|c|c|c|c|c|}
\hline Study site & $\begin{array}{l}\text { NDVI vs. } \\
\text { max. temp. }\end{array}$ & $\begin{array}{l}\text { NDVI vs. } \\
\text { min. temp. }\end{array}$ & $\begin{array}{l}\text { NDVI vs. } \\
\text { mean temp. }\end{array}$ & $\begin{array}{l}\text { NDVI vs. } \\
\text { prescipitation }\end{array}$ & $\begin{array}{c}\text { NDVI vs. } \\
\text { sun shine }\end{array}$ & $\begin{array}{c}\text { NDVI vs. relative } \\
\text { humidity }\end{array}$ & $\begin{array}{l}\text { NDVI vs. } \\
\text { evaporation }\end{array}$ \\
\hline Ganye & $0.072 *$ & $0.319^{\mathrm{NS}}$ & ----- & $0.005^{* * *}$ & $0.006 * * *$ & NA & NA \\
\hline Yola & $0.201^{\mathrm{NS}}$ & $0.000 * * *$ & ----- & $0.672^{\mathrm{NS}}$ & $0.768^{\mathrm{NS}}$ & $0.129^{\mathrm{NS}}$ & $0.263^{\mathrm{NS}}$ \\
\hline Gyawana & $0.011^{* *}$ & $0.058 *$ & ----- & $0.000 * * *$ & NA & $0.015 * *$ & NA \\
\hline Mubi & NA & NA & ------ & $0.109^{\mathrm{NS}}$ & NA & NA & \\
\hline
\end{tabular}

NA: Not Available; NS: None Significance * p-value (10\%);** p-value (5\%);*** p-value (1\%); ${ }^{\text {ns }}$-value (not significant); Field survey, 2018

Method of data collection: A vegetation zone that is relatively free from human intervention in the state was identified and used for data collection in this research. The data was collected in December, 2018 spanning through January, 2019. Gurin Forest Reserve (GFR) with a total land mass cover of $163.8 \mathrm{~km}^{2}$ equivalent to $163,800,000 \mathrm{~m}^{2}$ was identified and selected, a total of 100 sample locations were chosen and their coordinate were recorded using Garmin 785 Global Positioning System (GPS) unit. Coordinate obtained were used for extraction of NDVI values from each of the land sat images (1988-2017). The average NDVI values extracted from each year was then used as a variable for correlation analysis with climatic variables.

The climatic data were obtained from four selected meteorological stations in the two ecological zones of the state. The region of Sub-Sudan savannah zone is represented by Mubi and Yola meteorological stations and Guinea savannah zone is represented by Ganye and Gywana meteorological stations. The climatic data obtained include maximum and minimum mean temperature, rainfall, sunshine hours and relative humidity; the data were obtained from January, 1988 to
December, 2017. Coordinate of the selected four stations and facilities were also recorded and plotted on a table showing station and local government areas (Table 1). Also, images of vegetation cover from 1988-2017 were down loaded from (USGS) website to obtain the NDVI.

Climate data: About 30 year's time series data of mean maximum and minimum temperature, rainfall, sunshine hours and relative humidity were obtained from four selected meteorological stations of Adamawa state Mubi (Mubi station), Upper Benue river Basin authority (Yola, and Ganye) and Savanna Sugar Company (Gywana). Standard deviation was used to check the validity of the data obtained (Table 2). Missing data were completed using interpolation techniques from close (difference of 5 years) as described by Turkes et al. (1995) modified and adopted by Elodoyin. In addition, satellite images were down loaded from USGS (United State Geological Survey) and used in this study.

\section{NDVI data:}

Data processing: In this research, prior to the use of images for any scientific analysis, data pre-processing 
Agric. J., 14 (5): 94-103, 2019

Table 2: Summarized climatic data from four meteorological stations (Ganye, Yola, Gyawana and Mubi) in Adamawa state

$$
\text { Ganye }
$$
Yola Gywana

Mubi

Ative Max. Min. Mean

Max. Min Mean Rainfall

Years Max. Min. Mean Rainfall Sunshine Max Min Mean Rainfall Sunshine humi GYA GYA GYA Rainfall RH MUB MUB MUB MUB RH MUB

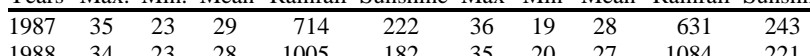

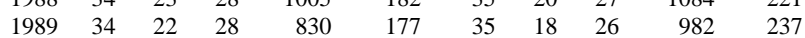

$\begin{array}{llllrllllll}1990 & 34 & 26 & 30 & 1117 & 204 & 34 & 19 & 27 & 824 & 234\end{array}$

$\begin{array}{lllllllllll}1991 & 35 & 27 & 31 & 929 & 194 & 33 & 20 & 27 & 863 & 210\end{array}$

$\begin{array}{lllllllllll}1992 & 34 & 30 & 32 & 700 & 170 & 34 & 17 & 26 & 869 & 222\end{array}$

$\begin{array}{lllllllllll}1993 & 33 & 31 & 32 & 1219 & 177 & 35 & 19 & 27 & 983 & 216\end{array}$

$\begin{array}{rrrrrrrrrrr}1994 & 33 & 32 & 33 & 869 & 185 & 34 & 19 & 26 & 925 & 215 \\ 1995 & 34 & 32 & 33 & 1093 & 190 & 36 & 19 & 27 & 1081 & 244\end{array}$

$\begin{array}{lllllllllll}1995 & 34 & 32 & 33 & 1093 & 190 & 36 & 19 & 27 & 1081 & 244\end{array}$

$\begin{array}{lllllllllll}1996 & 36 & 31 & 33 & 1108 & 188 & 34 & 19 & 26 & 1010 & 227\end{array}$

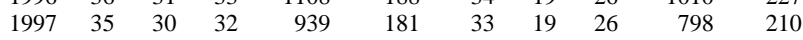

$\begin{array}{lllllllllll}1998 & 35 & 28 & 32 & 1011 & 178 & 34 & 20 & 27 & 1023 & 205\end{array}$

$\begin{array}{lllllllllll}1999 & 34 & 26 & 30 & 1018 & 180 & 31 & 20 & 26 & 1126 & 215\end{array}$

$\begin{array}{rrrrrrrrrrr}2000 & 33 & 24 & 29 & 1243 & 188 & 32 & 19 & 26 & 948 & 210\end{array}$

$\begin{array}{lllllllllll}2001 & 34 & 23 & 28 & 1115 & 199 & 34 & 20 & 27 & 917 & 213\end{array}$

$\begin{array}{lllllllllll}2002 & 33 & 23 & 28 & 1088 & 220 & 36 & 19 & 28 & 657 & 216\end{array}$

$\begin{array}{lllllllllll}2003 & 33 & 23 & 28 & 928 & 244 & 38 & 19 & 28 & 785 & 253\end{array}$

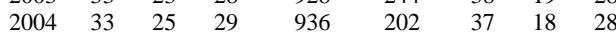

$\begin{array}{lllllllll}2005 & 33 & 27 & 30 & 900 & 237 & 34 & 23 & 29\end{array}$

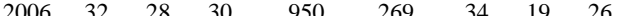

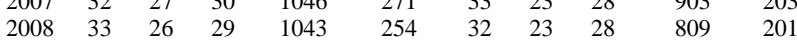

$\begin{array}{lllllllllll}2009 & 33 & 24 & 29 & 884 & 227 & 35 & 23 & 29 & 1063 & 218\end{array}$

$\begin{array}{lllllllllll}2010 & 34 & 23 & 28 & 878 & 205 & 33 & 23 & 28 & 1062 & 223\end{array}$

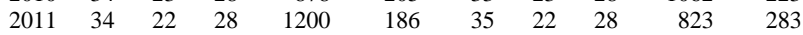

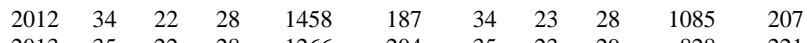

$\begin{array}{rrrrrrrrrrr}2013 & 35 & 22 & 28 & 1266 & 204 & 35 & 23 & 29 & 828 & 221 \\ 2014 & 34 & 22 & 28 & 1197 & 198 & 34 & 22 & 28 & 1015 & 230\end{array}$

$\begin{array}{rrrrrrrrrrr}2014 & 34 & 22 & 28 & 1197 & 198 & 34 & 22 & 28 & 1015 & 230 \\ 2015 & 35 & 23 & 29 & 1140 & 208 & 34 & 23 & 28 & 979 & 222\end{array}$

$\begin{array}{lllllllllll}2016 & 34 & 19 & 26 & 1253 & 224 & 35 & 23 & 29 & 1260 & 228\end{array}$

$\begin{array}{lllllllllll}2017 & 33 & 19 & 26 & 1370 & 223 & 36 & 22 & 29 & 921 & 221\end{array}$

Table 3: Landsat data missions

\begin{tabular}{lll}
\hline Year & Satellite & Sensor \\
\hline $1972-1981$ & Landsat 1, 2 and 3 & MSS \\
$1982-1984$ & Landsat 4 & MSS and TM \\
$1985-1993$ & Landsat 5 & TM MSS \\
$1994-1999$ & Landsat 6 & ETM (Failed mission) \\
$1999-2012$ & Landsat 7 & ETM $^{+}$ \\
$2012-2017$ & Landsat 8 & OLI \\
\hline
\end{tabular}

United State geological survey

was required which included geometric correction, atmospheric correction and the sub-setting of the sample study area. Table 3 provide important information about the land surface reflectance in each spectral band. This information helped in making decisions on combining of the spectral bands that were useful in carrying out NDVI for the study, image pre-processing stage which prepares data for subsequent analysis. A number of pre-processing operations that are being carried out on the Landsat images including the following: the study area is contained in one sample frame of the Landsat data which the area of interest was delineated. The pre-processing was carried out on individual image before delineation of the study area. The delineated image was then used for creating an Area of Interest (AOI) for ease of further processing and analysis. The interpretation of Landsat image was enhanced by increasing apparent contrast between various features in the scene. This includes radiometric and atmospheric corrections. Geometric correction was not carried out in this study since the investigation involve analysis of single image, thus, there was no need for this process.

NDVI creation and interpretation: NDVI is a mathematical calculation of reflectance in red and NIR bands. In this study Landsat data were used (Landsat 5, Landsat 7 and Landsat 8 images) for Landsat 5 (1988 and 1998), Landsat 7 (2002) and Landsat 8 (2017). In Landsat data 5 and 7 (red-band 3 and NIR-band 4) while in Landsat 8 (red-4 and NIR-5).

NDVI quantifies vegetation by measuring the difference between near-infrared (which vegetation strongly reflects) and red light (which vegetation absorbs). NDVI is a measure of the difference in reflectance between these wavelength ranges. NDVI takes values between -1 and 1 with values 0.5 indicating dense vegetation and values $<0$ indicating no vegetation.

To create NDVI maps with the image analysis toolbar in ArcGIS, imagery with red and NIR bands is needed. The 4 images were imported into ArcGIS environment for processing. First, Image Analysis Toolbar need to be enabled (Windows>Image Analysis) in ArcMap. The image analysis window will be displayed in ArcMap. Second, under image analysis options, select the red band and the near infrared band. In the NDVI tab the red band is "band 3" and the NIR band is "band 4" for 
Agric. J., 14 (5): 94-103, 2019

Landsat 5 and 7 while in Landsat red band is 4 and NIR is 5 for the case of this study. The option of "Scientific Output" was chosen in order to obtain values range from -1 to 1 . The image layer highlighted was checked and NDVI icon with the sign of leave green was then click to run the NDVI computation. This process was repeated on each of the images (1988, 1998, 2002 and 2017). The area of interest was imported as a shape file in order to subset the NDVI image for further analysis. The other land cover types in the NDVI map such as water bodies, built up areas, bare surface etc were masked out and only vegetation cover was further used for analysis. This was done in order to focus only on the analysis of vegetation cover (Maisongrande et al., 2004).

Radiometric correction: Digital sensors record the intensity of Electromagnetic Radiation (ER) from each spot viewed on the Earth's surface as a Digital Number (DN) for each spectral band. The exact range of DN that a sensor utilizes depends on its radiometric resolution. For example, a sensor such as Landsat Multi Spectral Scanner (MSS) measures radiation on a 0-63 DN scale whilst Landsat TM and Operational Land Imager (OLI) measure it on a $0-255$ scale. Although, the DN values recorded by a sensor are proportional to up welling ER (radiance), the true units are $\mathrm{Wm}^{-2} \mathrm{ster}^{-1} \mu \mathrm{m}^{-1}$. For purpose of this research, DN values recorded by sensor were converted to spectral radiance, the spectral radiance to apparent reflectance. This was carried out because the study is interested in the extraction of NDVI values for correlation with the climatic variables obtained from the weather stations (Stockli and Vidale, 2004).

Atmospheric correction: Sun illumination, weather disturbances and the production of shadows reduce the amount of extractable data from satellite images. This causes haze due to scattering or emission of electromagnetic radiation from the atmosphere that should be removed before any further processing. The most serious atmospheric impact arises from diffusing of light by particles suspended in air as depicted by Rayleigh's law which increments towards shorter higher energy wavelengths. Environmental Visualization Imager (ENVI) radiometric correction module used to rescale Landsat-8 data from quantized DNs to Top-of-Atmosphere (TOA) radiance, the output TOA radiance then resorting from Band Sequential (BSQ) to Band Interleaved by Line (BIL) to be appropriate for the following Fastline-of-Sight Atmospheric Analysis of Spectral Hybercubes (FLAASH) atmospheric correction (Stockli and Vidale, 2004).

Method of data analysis: In this study, Pearson correlation coefficient was used to check the strength of relations between NDVI and the related climate elements (i.e., temperature, precipitation, relative humidity and sunshine hours) and regression analysis was further used to identify the effectiveness of each climate elements on vegetation cover change during the period of 1988-2017.

\section{RESULTS AND DISCUSSION}

In order to identify the major climate elements affecting vegetation cover, the NDVI values at the 4 meteorological stations from the two ecological zones were extracted from the multi-temporal data obtained from the lad-sat imageries and then correlation coefficients was computed based on the times series data on NDVI, precipitation, temperature, relative humidity and sunshine hours. The analytical results Table 1 indicated that NDVI had a positive correlation with precipitation and temperature $(\mathrm{p}=0.672)$ in Yola and Gyawana for three decades followed with marginal negative correlation $(\mathrm{p}=0.000)$ in the last three decades. Ganye in the same period had slightly stable precipitation with positive correlation $(p=0.005)$ while Mubi recorded remarkable decreased of precipitation slightly negative correlation ( $\mathrm{p}=0.109$ ). But a slightly negative correlation with relative humidity and sunshine hours at Yala ( $=0.129)$, Gyawana $(p=0.015)$ and Ganye. The correlation between NDVI and precipitation is generally, positive. Evaporation, sun shine and relative humidity shows similar negative correlation in both study sites Yala (0.768; 0.129 0.263), Gyawana (0.015) and Ganye. Annual maximum temperature had noticeable increased during the study period in both study sites 2003 was recorded highest $43^{\circ} \mathrm{C}$ while 2000 was recorded lowest $31^{\circ} \mathrm{C}$ with no significant correlation in Yola $(\mathrm{p}=0.201)$.

Trend of climatic element in the study area and its effect on vegetation cover using regression analysis: In Ganye (Fig. 2a) maximum temperature trend exhibited a positive slope of the model line indicating overall increased in maximum temperature with time. Slope of 0.022/year, implies that on the average, the temperature increased at the rate of $0.22^{\circ} \mathrm{C}$ per year. The value of fitting coefficient is $R^{2}=(0.111)$, the slope indicated an increment per annum. The low value showed the erratic nature of the maximum temperature within the study area. The $p$-value $(p=0.072)$ indicated that the level of maximum temperature increase is significant.

While the mean annual minimum temperature (Fig. 2b), trend showed an increased with slope value of 0.045 year and the value of fitting coefficient is $\mathrm{R}^{2}=(0.035)$, this value showed nature of the empirical and model data of minimum temperature within the study area. The $p$-value $(p=0.319)$ indicated that the minimum temperature increase is in-significance.

However, Ganye (Fig. 2c), the mean annual average of maximum and minimum temperature changes over period of time indicated a significant increased with a 
Agric. J., 14 (5): 94-103, 2019

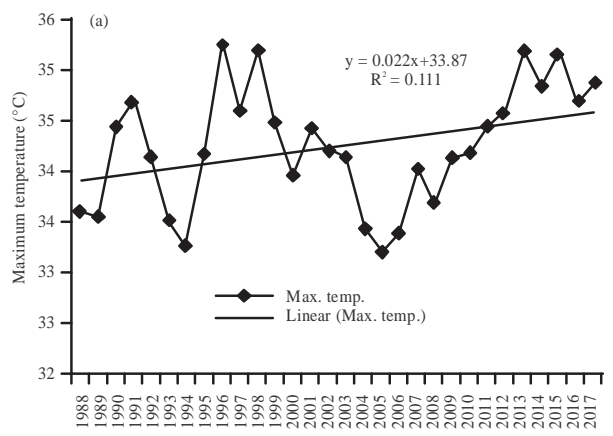

Years (sec)

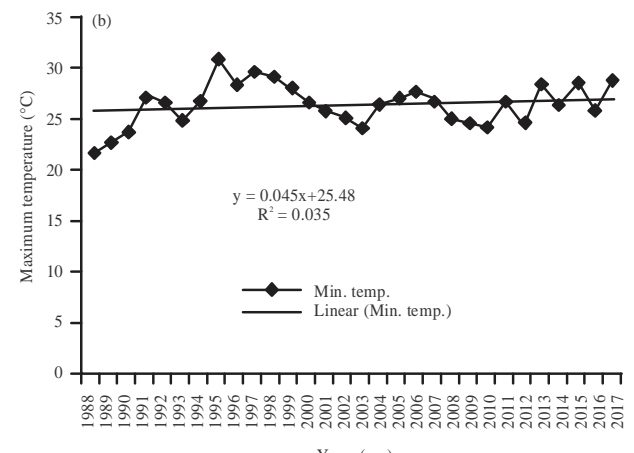

Years (sec)

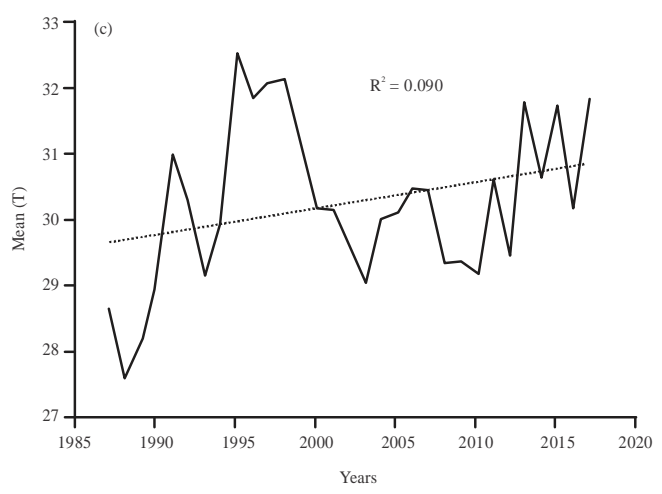

Fig. 2(a-c): a) Ganye mean annual maximum temperature trends 1988-2017 (b) Ganye mean annual minimum temperature trends (1988-2017) and (c) Ganye mean annual temperature trends 1988-2017 (mean of maximum and minimum)
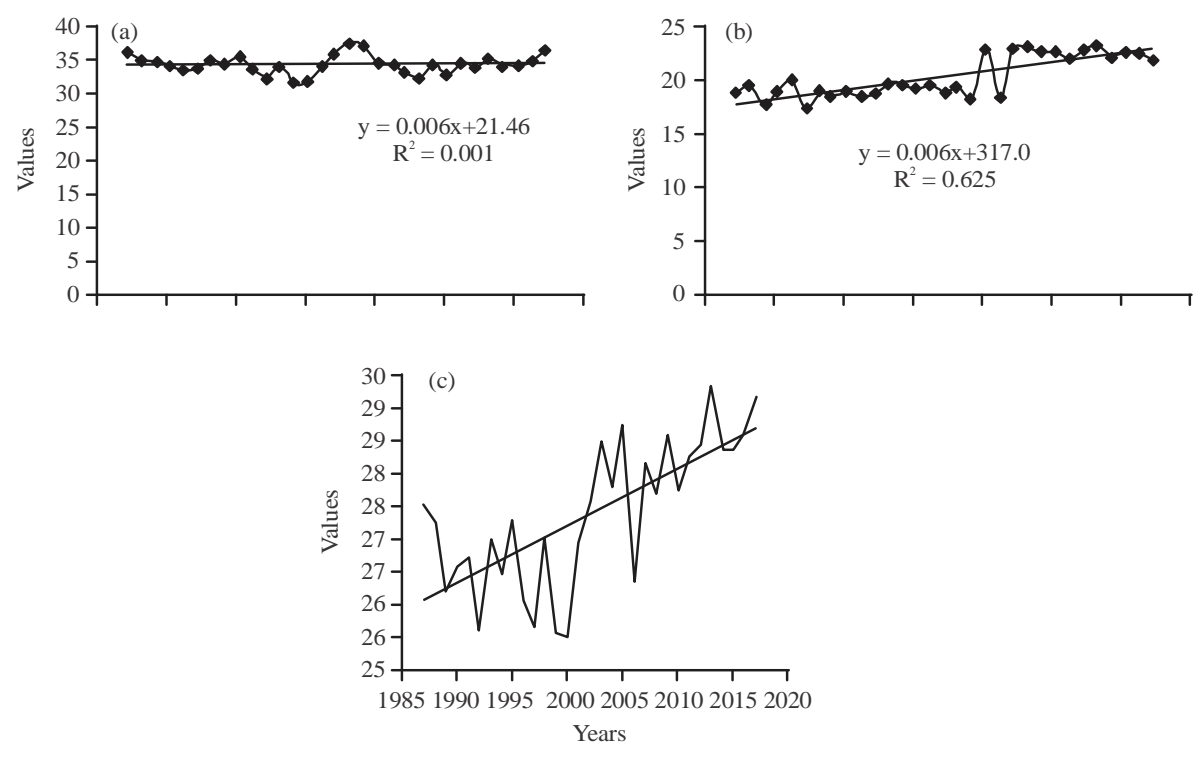

Fig. 3(a-c): (a) Yola mean annual maximum temperature trends (1988-2017) (b) Yola mean annual minimum temperature trends (1988-2017) and (c) Yola mean annual temperature trends 1988-2017 (mean of maximum and minimum)

high value coefficient of determination $\left(R^{2}=0.090\right)$. This analysis has indicated a mild increased of temperature of
Ganye from 1988-2017. In Yola (Fig. 3a), the mean minimum temperature trend indicated increased with a 
Agric. J., 14 (5): 94-103, 2019
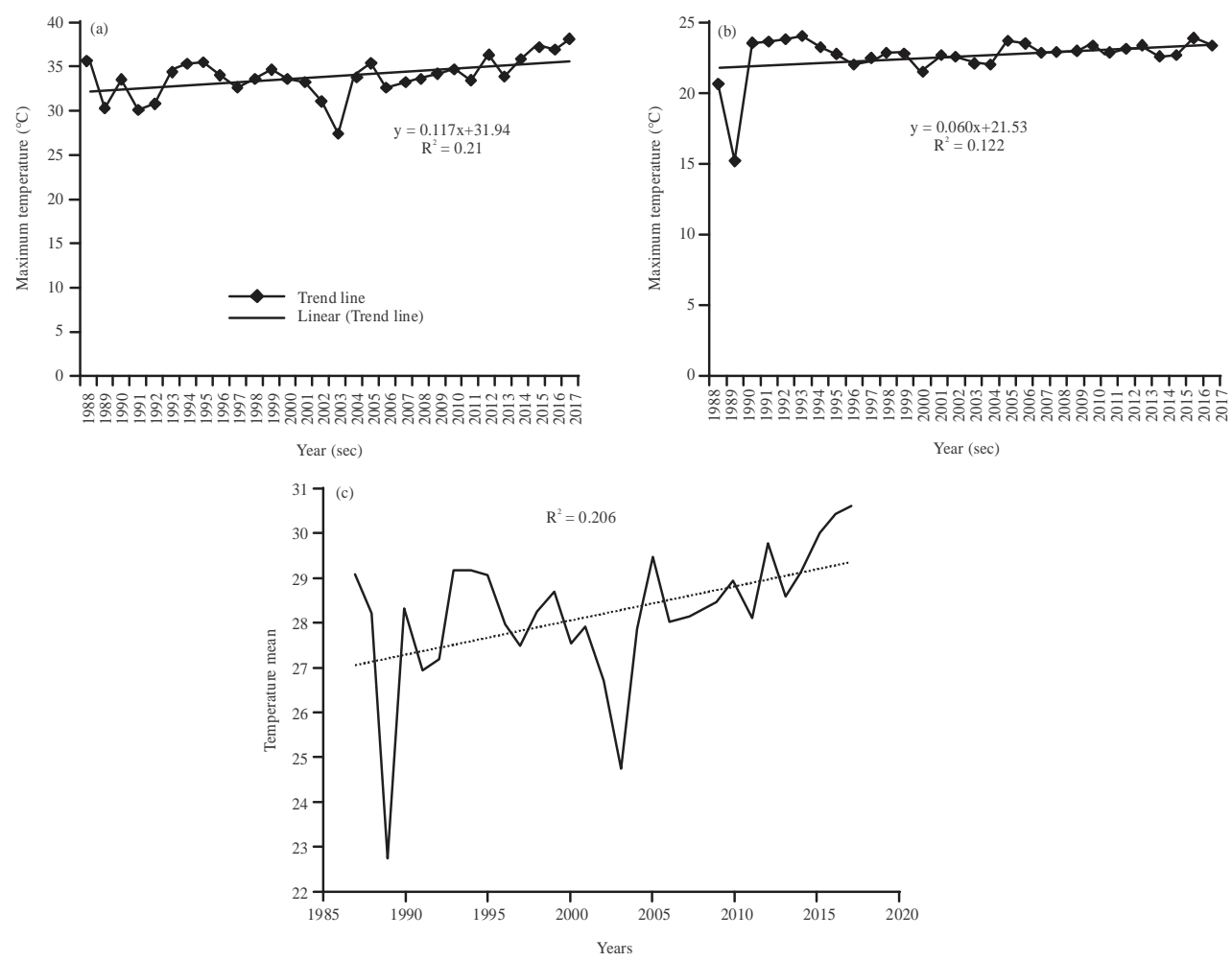

Fig. 4(a-c): a) Gyawana mean annual maximum temperature trends (1988-2017), (b) Gyawana mean annual minimum temperature trends (1988-2017) and (c) Gyawana mean annual temperature trends 1988-2017 (mean of maximum and minimum)

positive slope value of 0.0064/year and the value of fitting coefficient is $\left(\mathrm{R}^{2}=0.0017\right)$, this value shows therelationship between the empirical and model data of maximum temperature within the study area. The p-value ( $p=0.201)$ indicated insignificance increased.

While the mean minimum temperature trend (Fig. 3b) showed an increase with slope value of 0.165 /year and the value of fitting coefficient is $\left(R^{2}=0.625\right)$. The $p$-value $(\mathrm{p}=0.000)$ indicated significance increase.

However, the mean annual maximum and minimum temperature trend in Yola (Fig. 3c) showed highest variation in temperature value of $29.1^{\circ} \mathrm{C}$ was recorded in 2017 and a minimum value of $25.5^{\circ} \mathrm{C}$ in 2000 . The mean annual maximum and minimum temperature indicated a high significant increased with a value of fitting coefficient of determination $\left(\mathrm{R}^{2}=0.506\right)$.

In Gyawana (Fig. 4a), the trend showed highest variation in minimum temperature value of $38^{\circ} \mathrm{C}$ in 2007 and a minimum value of $27^{\circ} \mathrm{C}$ in 2003 . The mean annual maximum temperature indicated a significance increased with a value of fitting coefficient of $\left(\mathrm{R}^{2}=0.21\right)$ and a slope value of 0.117 year $^{-1}$. The $p$-value $(\mathrm{p}=0.011)$ indicated significant increase in maximum temperature.

While the trend showed highest variation in minimum annual temperature of $24^{\circ} \mathrm{C}$ in 2016 and the lowest value of $15^{\circ} \mathrm{C}$ in 1988 (Fig. 4b). The mean annual minimum temperature indicated significance increase with value of fitting coefficient of $\left(\mathrm{R}^{2}=0.12\right)$ and a slope value of 0.060 year $^{-1}$. The $p$-value $(p=0.058)$ indicated significance increased in minimum temperature.

The annual mean maximum and minimum temperature trend in Gywana (Fig. 4c) showed positive variation with highest temperature value of $31^{\circ} \mathrm{C}$ in 2017 and lower temperature value of $23^{\circ} \mathrm{C}$ in 1989 . The trend of change over time indicated significant increased with value of fitting coefficient of $\left(\mathrm{R}^{2}=0.206\right)$.

Figure 5 a shows the trend of annual average rainfall changes in Ganye overtime with a slope value of 9.617/year and fitting coefficient value of $\mathrm{R}^{2}=(0.247)$. The $\mathrm{p}$-value $(\mathrm{p}=0.005)$ showed significant changes in the distribution of rainfall.

In Yola (Fig. 5b) the trend of annual average rainfall changes over time with slope value of 1.221 /year and fitting of coefficient value of $\mathrm{R}^{2}=0.006$. The $\mathrm{p}$-value $(p=0.672)$ showed in-significance increase in rainfall distribution.

In Gyawana (Fig. 5c) the trend of annual average rainfall over time indicated significant increased with slope value of 6.658/year and fitting coefficient value of $\mathrm{R}^{2}=0.572$. The $\mathrm{p}$-value $(\mathrm{p}=0.000)$ indicated significance increased in rainfall distribution. 
Agric. J., 14 (5): 94-103, 2019
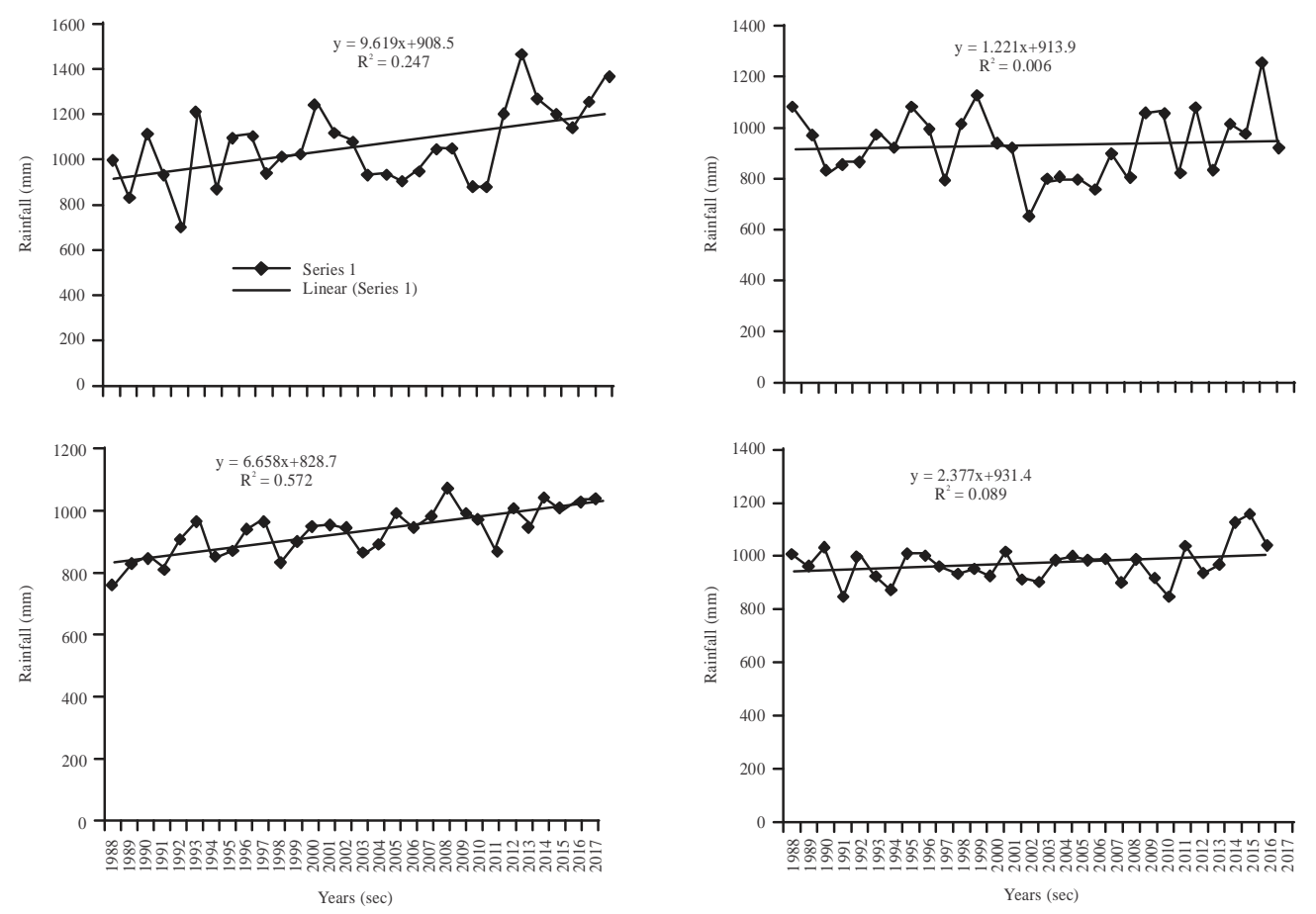

Fig. 5(a-d): (a) Trends for the annual average rainfall of Ganye, (b) Trends for the annual average rainfall of Yola (c) Trends for the annual average rainfall of Gyawana and (d) Trends for the annual average rainfall of Mubi (MUBI annual rainfall (mm))
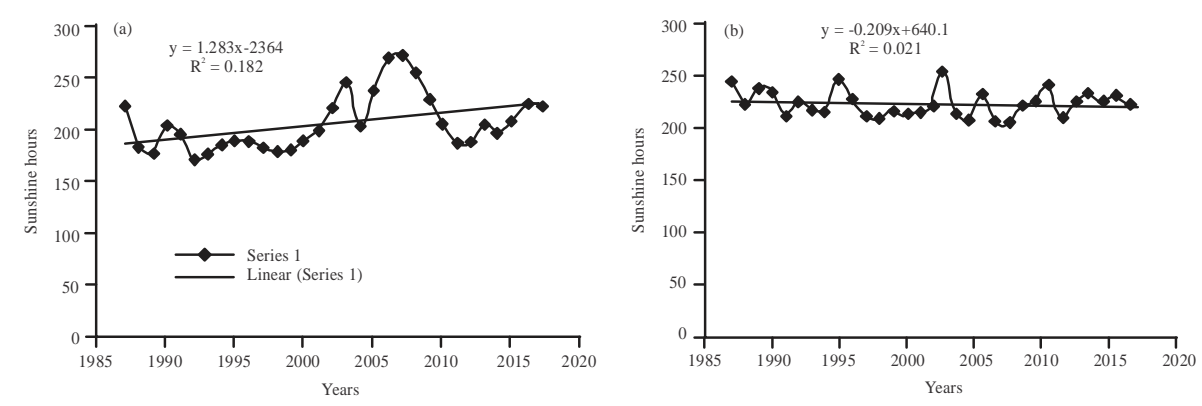

Fig. 6(a b): (a) Average of the annual sunshine hours of Ganye and (b) Average of the annual sunshine hours of Yola

In Mubi (Fig. 5d) the trend of average annual rainfall over time indicated significant increased with slope value of $2.377 /$ year and fitting coefficient value of $R^{2}=(0.089)$. The $p$-value $(p=0.109)$ indicated insignificance increase in the annual rain fall distribution.

Sun shine in Ganye (Fig. 6a), the trend of the annual average sunshine hours over time indicated a slope value of 1.283/year and fitting coefficient value of $\left(\mathrm{R}^{2}=0.182\right)$. The $p$-value $(p=0.006)$ indicated significant increase in sunshine hours.

In Yola (Fig. 6b), the trend of change in the annual average sunshine hours over period of time indicated a significant decreased in the slope with the negative value of $-0.2094 /$ year and fitting coefficient of $\left(R^{2}=0.021\right)$. The $\mathrm{p}$-value $(\mathrm{p}=0.768)$ have postulated in-significance decrease of the annual sunshine hours.

The annual average relative humidity in Yola (Fig. 7a), over period of time have a significant variations with increased in slope value of 0.176/year and the fitting coefficient value is $\mathrm{R}^{2}=0.0793$ and $\mathrm{p}$-value $(p=0.129)$ indicated insignificance increase in the relative humidity.

In Gyawana (Fig. 7b), the annual average relative humidity over period of time have significantly increased with slope value of 0.358 /year and fitting coefficients value of $\left(R^{2}=0.193\right)$. The $p$-value $(p=0.015)$ indicated significance increase of average relative humidity. 
Agric. J., 14 (5): 94-103, 2019
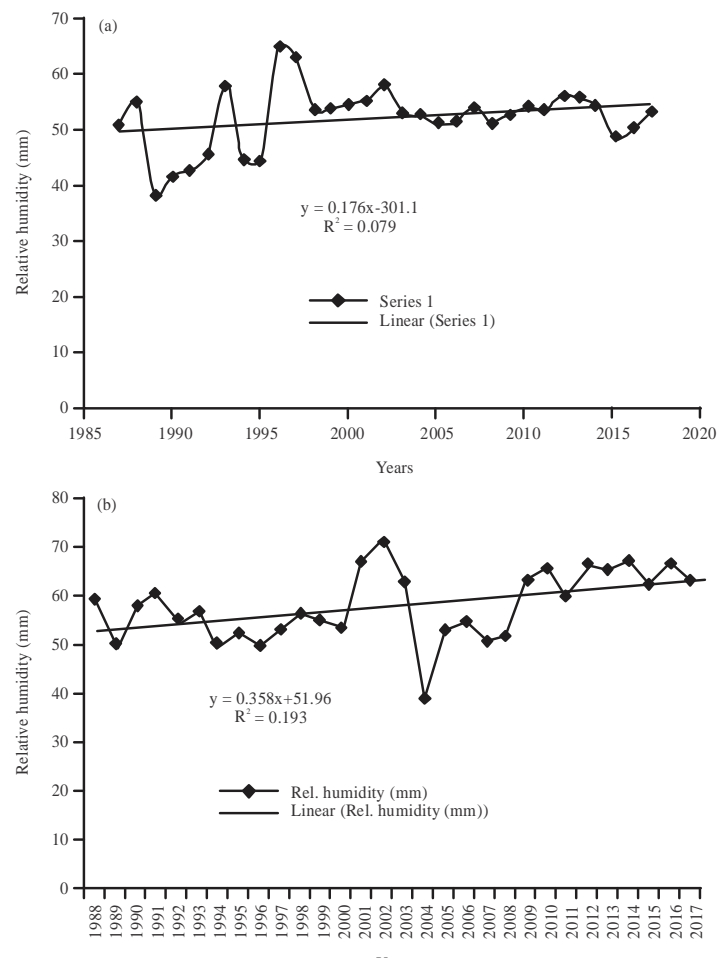

Fig. 7(a-b): (a) Annual average of relative humidity of Yola and (b) Annual average of relative humidity of Gyawana (Gyawana relative humidity (mm))

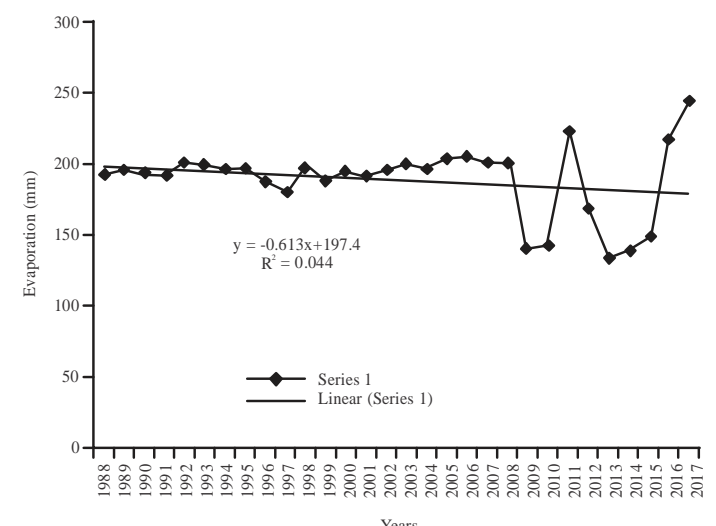

Years

Fig. 8: Annual average of evaporation of Yola

The annual average evaporation (Fig. 8), over period of time have significant increase in the trend with slope value of -0.613 year and fitting coefficients value of $\left(\mathrm{R}^{2}=0.044\right)$. The $\mathrm{p}$-value $(\mathrm{p}=0.263)$ indicated no significant increase of the evaporation in Yola over the period of time.

The environment is a complex whole of, so, many interacting factors that influence every organism and all that surround and effect an organism is its environment.
Factors like light, temperature, precipitation, relative humidity, sun shine, evaporation and wind constitute the climate. Climate elements affect vegetation growth by changing soil moisture and heat energy. The correlation and regression analysis above indicated that precipitation and temperature are two primary climate parameters that directly impact vegetation growth in a positive fashion in Adamawa state. Finding of this research revealed that the vegetation cover of Adamawa state changes slightly in varying magnitude from 1988-2017 (30 years) due to the variation in the climatic factors. However, the negative shift in vegetation cover indicated that the vegetation is more sensitive to precipitation and temperature but it worthy to note that NDVI (vegetation cover) had a slight negative correlation with relative humidity, evaporation and sun shine at Yola and Mubi and positive correlation in Ganye and Gyawana, thus, the negative statistical correlation observed is mainly as a result of temperature effect. To detect the correlation between relative humidity, evaporation and vegetation cover the use of absolute measures (saturation deficit for example) is necessary. Therefore, further studies are expected. The behavior of the climatic elements such as precipitation and temperature, over the study period and the test of the relationship of the climatic elements on the vegetation cover represented by NDVI indicated that precipitation and temperature had strongest impact amongst other climatic elements that the research have examined. From the graphs above mean maximum and minimum temperature and mean annual precipitation in all the study sites during the study period, it is noticeable that there is linear relationship between precipitations; temperature and vegetation cover (NDVI).

\section{CONCLUSION}

Using an integrated method including Pearson correlation coefficient and regression analyses, this study investigated the relationship between vegetation cover (NDVI generated from Lad sat imageries) and the major climate elements from 4 meteorological stations in Adamawa state. The study concluded that there is a strong relationship between NDVI and climatic elements. Precipitation and temperature was found to be correlating with vegetation cover (NDVI) in all the study area (Yola, Mubi, Ganye and Gyawana) while evaporation, relative humidity and sun shine were negatively correlating with vegetation cover (NDVI) at Ganye and Gyawana.

\section{RECOMMENDATIONS}

The study recommends further investigations on vegetation dynamic responses to changes in the precipitation and temperature and to establish quantitative relations between them. In addition, further studies are required to detect the correlation between relative humidity, sun shine, evaporation and vegetation covers. 
Agric. J., 14 (5): 94-103, 2019

\section{REFERENCES}

Adebayo, A.A. and A.L. Tukur, 1999. Adamawa State in Maps. 1st Edn., Paraclete Press, Brewster, Massachusetts, USA., ISBN: 9789783515703 , Pages: 112.

Adebayo, A.A., 2010. Climate: Resource and Resistance to Agriculture. Federal University of Technology Yola, Girei, Nigeria, ISBN: 9789783859357, Pages: 48.

Adewumi, A.S., 2013. Analysis of land use/land cover pattern along the River Benue channel in Adamawa State, Nigeria. Acad. J. Interdiscip. Stud., 2: 95-108.

Akosim, C., P. Mbaya and H.D. Nyako, 2004. Evaluation of rangeland condition and stocking rate of Jibiro Grazing Reserve, Adamawa State. J. Arid Agric., 14: 35-37.

Du, M., S. Kawashima, S. Yonemura, X. Zhang and S. Chen, 2004. Mutual influence between human activities and climate change in the Tibetan Plateau during recent years. Global Planetary Change, 41: 241-249.

Eidenshink, J.C. and J.L. Faundeen, 1994. The $1 \mathrm{~km}$ AVHRR global land data set: First stages in implementation. Int. J. Remote Sens., 15: 3443-3462.

Fu, X.F., S.T. Yang, C.M. Liu, 2007. Changes of NDVI and their relations with principal climatic factors in the Yarlung Zangbo River Basin. Geo. Res., 26: 60-66.

Kaufmann, R.K., L. Zhou, R.B. Myneni, C.J. Tucker, D. Slayback, N.V. Shabanov and J. Pinzon, 2003. The effect of vegetation on surface temperature: A statistical analysis of NDVI and climate data. Geo. Res. Lett., Vol. 30, No. 22. 10.1029/2003GL018251

Maisongrande, P., B. Duchemin and G. Dedieu, 2004. VEGETATION/SPOT: An operational mission for the Earth monitoring, presentation of new standard products. Int. J. Remote Sens., 25: 9-14.
Nemani, R.R., C.D. Keeling, H. Hashimoto, W.M. Jolly and S.C. Piper et al., 2003. Climate-driven increases in global terrestrial net primary production from 1982 to 1999. Science, 300: 1560-1563.

Running, S.W. and R.R. Nemani, 1988. Relating seasonal patterns of the AVHRR vegetation index to simulated photosynthesis and transpiration of forests in different climates. Remote Sens. Environ., 24: 347-367.

Stockli, R. and P.L. Vidale, 2004. European plant phenology and climate as seen in a 20-year AVHRR land-surface parameter dataset. Int. J. Remote Sens., 25: 3303-3330.

Tucker, C.J. and P.J. Sellers, 1986. Satellite remote sensing of primary production. Int. J. Remote Sens., 7: 1396-1416.

Turkes, M., U.M. Sumer and G. Kilic, 1995. Variations and trends in annual mean air temperatures in Turkey with respect to climatic variability. Int. J. Climatol., 15: 557-569.

UNFCCC., 2007. Climatic change: Impact, vulnerabilities and adaptation in developing countries. United Nations Framework Convention on Climate Change, ?Rio de Janeiro, Brazil. http s://unfccc.i nt/resource/docs/publications/impacts.pdf.

Wylie, B.K., D.A. Johnson, E. Laca, N.Z. Saliendra and T.G. Gilmanov et al., 2003. Calibration of remotely sensed, coarse resolution NDVI to CO2 fluxes in a sagebrush-steppe ecosystem. Remote Sens. Environ., 85: 243-255.

Yang, Z., C. Li, G.H. Huang and Y. Cai, 2010. Analysis of relationships between NDVI and climatic/hydrological parameters in the Yellow River basin. Int. J. Environ. Pollut., 42: 166-183. 